\title{
KINETIC ANALYSIS OF THERMAL DEGRADATION OF Cedrela odorata, Marmaroxylon racemosum AND Tectona grandis FROM TIMBER INDUSTRY
}

\author{
Camily Daiane Cavinato ${ }^{1}$ \\ Matheus Poletto ${ }^{2, \$}$ \\ https://orcid.org/0000-0003-2317-2713
}

\begin{abstract}
Thermal analysis is a powerful tool to predict the composition and thermal stability of different materials. In this work, thermogravimetric analysis of Cedrela odorata, Marmaroxylon racemosum and Tectona grandis was carried out at four different heating rates $\left(5^{\circ} \mathrm{C} \cdot \mathrm{min}^{-1}, 10^{\circ} \mathrm{C} \cdot \mathrm{min}^{-1}, 20^{\circ} \mathrm{C} \cdot \mathrm{min}^{-1}\right.$ and $\left.40{ }^{\circ} \mathrm{C} \cdot \mathrm{min}^{-1}\right)$ in a non-isothermal condition. The degradation kinetics was evaluated based on Flynn-Wall-Ozawa and Criado methods. The half-life time of wood degradation reaction was also studied. The wood thermal degradation process in an oxidizing atmosphere can be divided in dehydration, devolatilization, and combustion. The kinetic results revels apparent activation energy values of $130-240 \mathrm{~kJ} \cdot \mathrm{mol}^{-1}$ for Tectona grandis, $150-191 \mathrm{~kJ} \cdot \mathrm{mol}^{-1}$ for Marmaroxylon racemosum and $188-205 \mathrm{~kJ} \cdot \mathrm{mol}^{-1}$ for Cedrela odorata, when conversion values ranged from $0,1-0,5$. The most probable degradation mechanism for wood species studied is a diffusion model based on a three-dimensional diffusion. Cedrela odorata presented the lowest reaction half-life time while Marmaroxylon racemosum showed the highest. On the basis of these results, it can be concluded that Flynn-Wall-Ozawa and Criado methods associated with half-life time of reaction may contribute to better understand the wood degradation before use it in polymer composites.
\end{abstract}

Keywords: Activation energy, Criado method, Flynn-Wall-Ozawa, thermogravimetry, thermal stability.

\section{INTRODUCTION}

The concern of society with environmental issues is a driving force that constantly seeks that new alternative in different industry sectors can minimize waste generation and promote recycling initiatives that can contribute to obtain sustainable processes (Barbos et al. 2020, Gheith et al. 2019). The forestry sector is known for using natural resources on a large scale and for generating large amounts of wood waste (Mohd Yusof et al. 2020). The main part of these lignocellulosic residues is commonly used for energy generation (Poletto 2017) but some are disposed of in landfills. In Brazil, it is estimated that about 30 million tons of wood waste are generated annually (Ramos et al. 2018). The timber industries are responsible for $91 \%$ of this annual generation (Ramos et al. 2018).

In the Brazilian Amazon Region, it is estimated that more than 8 million cubic meters of wood waste are generated annually (Ramos et al. 2018). In addition, $59 \%$ of native wood is lost until value added wood products can be obtained (Batista et al. 2015). The possibility of reusing or recycling this lignocellulosic waste to be used in the sector itself or, to be used as reinforcement in composite materials are interesting alternatives both from a financial and environmental point of view (Adhikary et al. 2008, AlMaadeed et al. 2014).

\footnotetext{
${ }^{1}$ University of Caxias do Sul (UCS), Chemical Engineering, Caxias do Sul, Brazil.

${ }^{2}$ University of Caxias do Sul (UCS), Postgraduate Program in Engineering of Processes and Technologies (PGEPROTEC), Caxias do Sul, Brazil. 
When used as reinforcement in composites, wood waste scan replace inorganic fillers, due to their low abrasion during processing, lower density, lower cost and biodegradability (AlMaadeed et al. 2014, Neves et al. 2019). However, wood also has some drawbacks, such as low adhesion, moisture absorption and lower thermal stability than non-lignocellulosic materials (Adhikary et al. 2008, AlMaadeed et al. 2014).

The low wood thermal stability of wood is a limitation to use it in polymeric composite formulations. Traditionally, these materials are prepared through mixtures with polymers in the molten state, where, in most cases, the processing temperature is above $200{ }^{\circ} \mathrm{C}$. However, even at temperatures below $200{ }^{\circ} \mathrm{C}$, some wood components can undergo thermal degradation, depolymerization and discoloration, compromising the performance of wood polymer composites (Poletto 2016, Shebani et al. 2008). The extractives might create an unfavorable effect on the thermal stability of wood thermoplastic composites, because their oxidation tends to promote wood degradation during the mixing of wood with thermoplastic matrices (Shebani et al. 2009). Sheshmani et al. (2012) reported that wood extractives may tend to migrate to wood flour surface during the preparation of wood thermoplastic composites at processing temperatures higher than $170{ }^{\circ} \mathrm{C}$. This behavior might result in their accumulation in the wood-polymer interphase wich may reduce the adhesion promote by the usage of coupling agent and consequently decrease the composite mechanical properteis (Sheshmani et al. 2012). So, prior knowledge about wood thermal degradation kinetics is an important tool in choosing the wood species that may be used for the development of thermoplastic composites. Evaluate the thermal decomposition of wood is essential for obtain the full potential of this material, in order to use the best combination of processing, structure and properties in the manufacture of the composite (Shebani et al. 2008).

In this context, the present work evaluates the thermal stability and degradation kinetics of three wood species from Brazilian Amazon region. Kinetics were based on determine the activation energy, solid state degradation mechanism and half-life time of degradation reaction.

\section{Theoretical background}

\section{Flynn-Wall-Ozawa method}

Flynn-Wall-Ozawa (FWO) proposed an isoconversional method in which the activation energy (Ea) values can be obtained without previous knowledge about the reaction mechanisms (Ali et al. 2017, Neves et al. 2020). The FWO method is described by Equation 1.

$$
\log \beta=\log \left[\frac{A E_{a}}{g(\alpha) R}\right]-2,315-0,4567 \frac{E_{a}}{R T}
$$

Where $\beta$ is the heating rate, $A$ is the pre-exponential factor, $g(\alpha)$ is a function of the conversion and $\mathrm{R}$ is the gas constant. Using several heating rates $(\beta)$ a linear relationship is verified by plotting $\log \beta$ vs. $1 / T$. The $E_{a}$ value can be obtained from the slope of the straight line (Neves et al. 2020).

\section{Criado method}

The method proposed by Criado and coworkers can be used to determine the reaction mechanism involved in a degradation process (Erceg et al. 2018, Sobek and Werle 2020). The method compares the shape of theoretical and experimental master plots. The most probable reaction mechanism is the one that presented the best fit between them. Theoretical master plots are given by Equation (2), while experimental master plots are described in Equation (3), based on the $Z(\alpha)$ function:

$$
\begin{aligned}
& Z(\alpha)=f(\alpha) g(\alpha) \\
& Z(\alpha)=\frac{d \alpha}{d T} \frac{E_{a}}{R} e^{\frac{E_{a}}{R T}} P(x)
\end{aligned}
$$


where $f(\alpha)$ and $g(\alpha)$ are the differential and integral form of the kinetic method (Erceg et al. 2018, Poletto et al. 2012), respectively; $\mathrm{d} \alpha / \mathrm{dT}$ is the rate of conversion and $\mathrm{P}(\mathrm{x})$ is an approximation of the temperature integral, in this study were used the fourth rational expression of Senum and Yang (Drozin et al. 2020) described in Equation (4):

$$
P(\mathrm{x})=\frac{x^{3}+18 x^{2}+88 x+96}{x^{4}+20 x^{3}+120 x^{2}+240 x+120}
$$

Where $\mathrm{x}=\mathrm{Ea} / \mathrm{RT}$.

\section{Half-life time of reaction}

The ASTM E698 (2018) was used to determine the half-life time $\left(t_{1 / 2}\right)$ of the wood degradation reaction. The kinetic parameters were obtained based on the Arrhenius equation described in Equation (5):

$$
k=Z e^{-(E a / R T)}
$$

Where $\mathrm{k}$ is the rate constant and $Z$ the pre-exponential factor, that according to ASTM E698 (2018) can be obtained as described in Equation (6):

$$
Z=\frac{\beta E a e^{(E a / R T)}}{R T^{2}}
$$

The half-life time of reaction was obtained from a $k$ value related to a fixed temperature, as proposed by ASTM E698 (2018) according to describe in Equation (7):

$$
t_{1 / 2}=\frac{0,693}{k}
$$

\section{MATERIALS AND METHODS}

\section{Materials}

Wood samples of Cedrela odorata L. (CED), Marmaroxylon racemosum Ducke Killip (MAR) and Tectona grandis (TEC)were provided by Madeireira Perimetral - Caxias do Sul, Rio Grande do Sul/Brazil. The samples were wastes from wood cutting without any type of previous chemical treatment. The wood samples were grounded in a knife mill until a particle size of $250 \mu \mathrm{m}$ was reached. All samples were oven dried at $105^{\circ} \mathrm{C}$ for $8 \mathrm{~h}$ before the tests.

\section{Thermogravimetric analysis (TGA)}

The analyzes were carried out in a Shimadzu thermogravimetric analyzer model TGA-50. A TGA analysis was performed at heating rates of $5{ }^{\circ} \mathrm{C} \cdot \mathrm{min}^{-1}, 10^{\circ} \mathrm{C} \cdot \mathrm{min}^{-1}, 20^{\circ} \mathrm{C} \cdot \mathrm{min}^{-1}$ and $40^{\circ} \mathrm{C} \cdot \mathrm{min}^{-1}$, with a temperature range of $23{ }^{\circ} \mathrm{C}$ to $700{ }^{\circ} \mathrm{C}$, in an atmosphere of synthetic air at a flow of $63 \mathrm{~mL} \cdot \mathrm{min}^{-1}$. The mass for each sample was approximately $10 \mathrm{mg}$. 

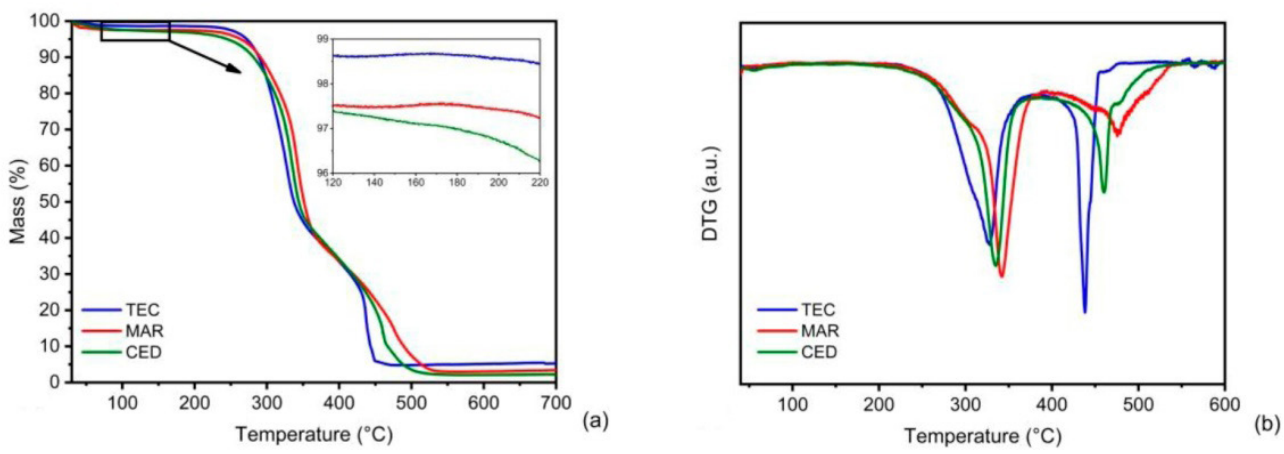

Figure 1:Thermogravimetric curves (a) and the first derivative curves (DTG) (b) of TEC, MAR and $\mathrm{CED}$ wood species studied at $10^{\circ} \mathrm{C} \cdot \mathrm{min}^{-1}$.

Figure 1 shows the thermogravimetric curves for all wood species studied at a heating rate of $10{ }^{\circ} \mathrm{C} \cdot \mathrm{min}^{-1}$. The wood thermal decomposition process under oxidizing atmosphere can be divided into 3 distinct stages of mass loss: dehydration, devolatilization, and combustion (Li et al. 2013).

In the dehydration stage, the removal of weakly bonded water molecules and hydrolysis of some extractive components present in wood were observed at temperature up to $200{ }^{\circ} \mathrm{C}$ with a minor mass loss ranged from 2-4 mass \%, depending of wood specie. This mass loss is more accentuated for CED, as can be seen in Figure 1(a). The temperature of $3 \mathrm{wt} \%$ of mass loss for CED was $178^{\circ} \mathrm{C}$, while MAR and TEC presented values of $231^{\circ} \mathrm{C}$ and $257^{\circ} \mathrm{C}$. As can be seen in the insert in Figure 1(a), it is possible to verify that in the temperature range between $180{ }^{\circ} \mathrm{C}-220^{\circ} \mathrm{C}$, where wood is commonly used as reinforcement in thermoplastic polymers, CED presents a more significant mass loss in relation to other species. CED starts a more pronounced degradation process at around $130^{\circ} \mathrm{C}$, while TEC initiate at $190^{\circ} \mathrm{C}$ and MAR close to $205^{\circ} \mathrm{C}$. This result may indicate that the use of CED as a reinforcement in thermoplastic polymers can lead to a composite with undesirable properties due to its low thermal stability. According to the literature (Tenorio and Moya 2013) the elimination of bound water associated with wood constituents, such as hemicellulose and cellulose, might occurs at around $160{ }^{\circ} \mathrm{C}$, which gradually decrease the wood thermal stability and can result in wood discoloration and depolymerization (Shebani et al. 2008). On the other hand, the extractive oxidation that also occurs below 200 ${ }^{\circ} \mathrm{C}$, tends to increase the acidity of wood and promote wood degradation reducing its mechanical properties (Shebaniet al. 2009).

The second stage (devolatilization) occurs between $200{ }^{\circ} \mathrm{C}$ and $400{ }^{\circ} \mathrm{C}$, as shown in Figure $1(\mathrm{~b})$. At this stage the majority of volatiles are released. The thermal cracking of three major wood compounds, hemicellulose, cellulose and lignin, is dominant (Lengowski et al. 2020) and the thermal reactivity goes on increasing as the reaction temperature increases ( $\mathrm{Li}$ et al. 2013, Oluoti et al. 2014). The devolatilization zone $\left(200{ }^{\circ} \mathrm{C}\right.$ to $400{ }^{\circ} \mathrm{C}$ ) is characterized by the formation of one shoulder and a well-defined peak at approximately $300^{\circ} \mathrm{C}$. As previous report in the literature hemicellulose reacts between $230{ }^{\circ} \mathrm{C}$ to $330^{\circ} \mathrm{C}$ (Balogun et al. 2014, Li et al. 2013, Oluoti et al. 2014), which may correspond to the shoulders in DTG curves observed in Figure 1(b). The cellulose generally degrades between $270{ }^{\circ} \mathrm{C}$ to $370{ }^{\circ} \mathrm{C}$ (Balogun et al. 2014, Li et al. 2013) and its degradation might be correspond to the first peak observed in Figure 1(b) for all wood species evaluated. CED and MAR presented temperature peaks associated to the cellulose degradation centred at 335 and $342{ }^{\circ} \mathrm{C}$, respectively, while for TEC this peak was less intense and occurred at $328{ }^{\circ} \mathrm{C}$. The thermal cracking of the main wood components can accelerate the polymer degradation if these wood species are used in composite formulations, which may result in a decrease of the polymer composite thermal stability (Shebani et al. 2009).

In the combustion stage that occurs between $400{ }^{\circ} \mathrm{C}$ and $550{ }^{\circ} \mathrm{C}$ a prominent peak centred at $438{ }^{\circ} \mathrm{C}$ can be seen for TEC wood in Figure 1(b). CED and MAR also presented peaks centred at $460{ }^{\circ} \mathrm{C}$ and $475{ }^{\circ} \mathrm{C}$, respectively. At this last stage, the massive thermal decomposition of lignin occurs. The residue obtained here is solid bio-char which further oxidized to form $\mathrm{CO}_{2}, \mathrm{CO}$, and steam (Li et al. 2013). In this stage, all wood components are degraded and mostly ashes are left (Tenorio and Moya 2013). 


\section{Kinetic analysis}

Figure 2(a) shows the dependence of apparent activation energy $\left(\mathrm{Ea}_{\mathrm{FWO}}\right)$ on conversion $(\alpha)$ for CED wood from conversion values between 0,1 and 0,5 . This conversion range was choosing because the main degradation process occurs at this interval. In addition, considering the usage of wood as reinforcement in composites, this conversion range include temperatures up to $350{ }^{\circ} \mathrm{C}$, that are above $200{ }^{\circ} \mathrm{C}$, the temperature commonly used to processing of wood polymer composites.

It is possible observe in Figure 2(a) that for CED the fitted lines are nearly parallel. This behavior may indicate that apparent Ea values can be closed and may also indicate a single reaction mechanism (Neves et al. 2020, Yao et al. 2008). TEC and MAR wood samples presented the same behavior (curves not showed). However, for TEC the apparent Ea values tend to increase at $\alpha$ values between 0,4-0,5, as shown in Figure 2(b), which may indicate that complex reactions may occurs at higher temperatures. At this stage the wood devolatilization occurs and the thermal cracking of main wood components takes place, which implies in several consecutive reactions (Cabeza et al. 2015, Ornaghi et al. 2020) increasing the apparent Ea.
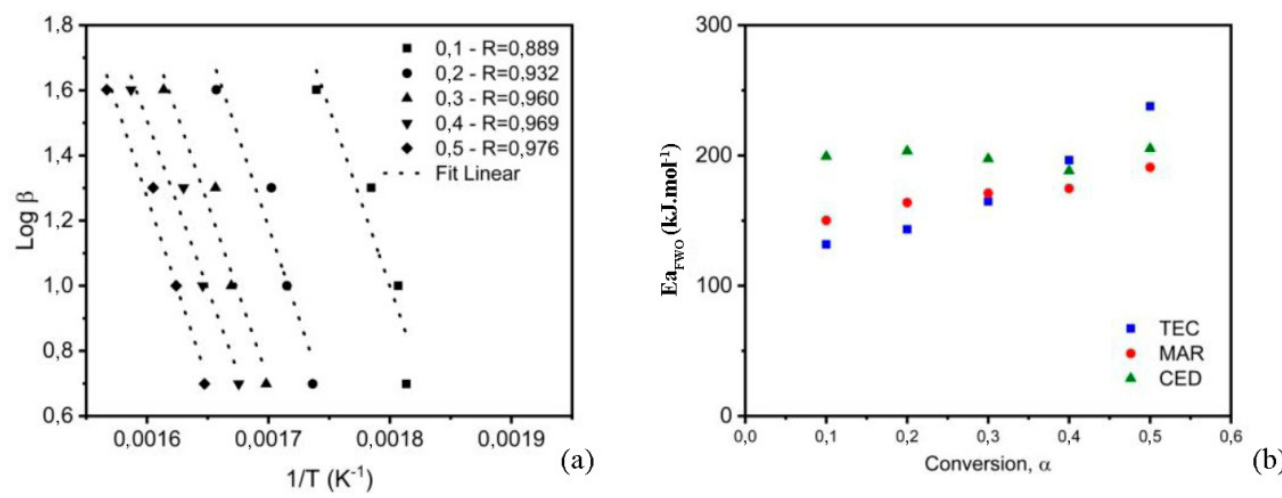

Figure 2: Apparent Ea obtained using FWO method for CED wood (a) and dependence of Ea on $\alpha$ determined by FWO method for all wood species studied.

The apparent Ea values for $\alpha$ values between $0,1-0,5$ ranged from $130 \mathrm{~kJ} \cdot \mathrm{mol}^{-1}$ to $240 \mathrm{~kJ} \cdot \mathrm{mol}^{-1}$ for TEC, $150 \mathrm{~kJ} \cdot \mathrm{mol}^{-1}$ to $191 \mathrm{~kJ} \cdot \mathrm{mol}^{-1}$ for MAR, while for CED ranged from $188 \mathrm{~kJ} \cdot \mathrm{mol}^{-1}$ to $205 \mathrm{~kJ} \cdot \mathrm{mol}^{-1}$. These results are in agreement with other results from the literature. Oluoti et al. (2014) obtained apparent Ea values from $120-150 \mathrm{~kJ} \cdot \mathrm{mol}^{-1}$ from TEC sample from Nigeria, when $\alpha$ values ranged from 0,1-0,5. Balogun et al. (2014) also used FWO method for evaluate the kinetic degradation of a TEC sample from Nigeria and obtained apparent Ea values ranging from $221 \mathrm{~kJ} \cdot \mathrm{mol}^{-1}$ to $250 \mathrm{~kJ} \cdot \mathrm{mol}^{-1}$ for $\alpha$ values between $0,15-0,5$. The wood thermal degradation is based on multiple reactions that presented a complex reaction mechanism (Slopiecka et al. 2012) which influenced in apparent Ea values.

\section{Generalized master-plot}

The experimental master curves $Z(\alpha)$, obtained from the use of Equation (3) are compared with the theoretical curves obtained from Equation (2) and the results are shown in Figure 3. The resolution of the Equation (3) was obtained through the use of experimental results in the heating rate of $10{ }^{\circ} \mathrm{C} \cdot \mathrm{min}^{-1}$ and the apparent Ea values obtained by the FWO method. The master curves show the simulated mechanisms. Theses mechanisms are separated into four groups: An, Dn, Rn, and Fn, which describe, respectively: nucleus formation processes for the propagation of thermal degradation; diffusion processes that are related to the ability to transfer mass throughout the material structure; reaction mechanisms controlled by the sample surface; and the random degradation of nuclei (Bianchi et al. 2011, Ornaghi et al. 2020). 

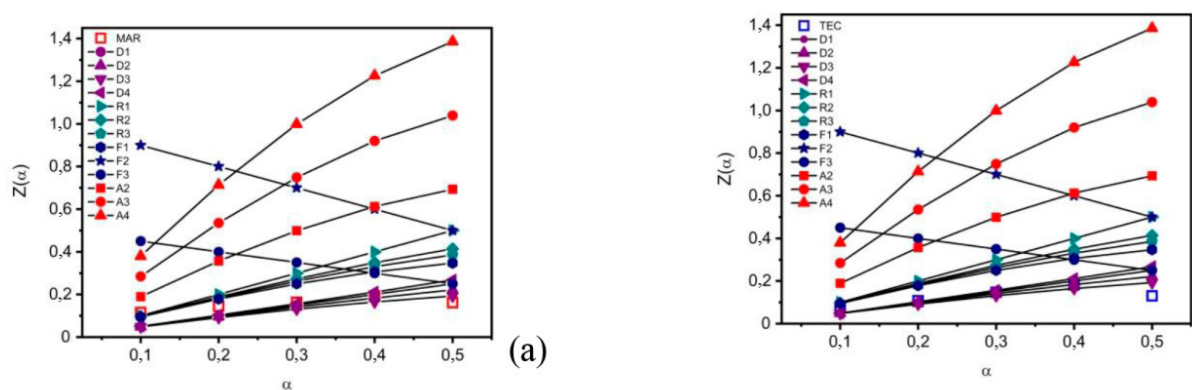

(b)

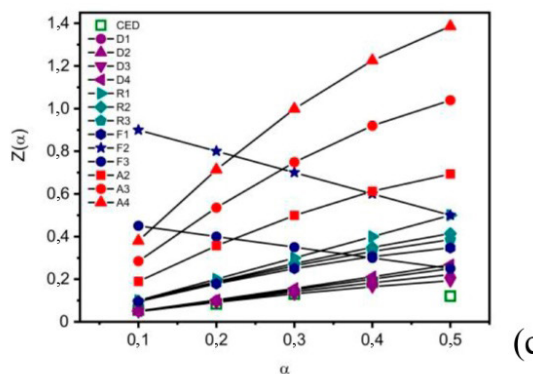

Figure 3: Comparison of theoretical and experimental master plots for all wood species evaluated.

The control of the thermal degradation process for wood species is basically done by diffusion (Dn) up to conversion values of 0,5 . The behavior of the species superimposed mainly on the D3 mechanism, probably the degradation reaction starts at the boundary of two phases, solid and gas (Sobek and Werle 2020). So, the reaction continues with the diffusion of gas into the solid medium (Sobek and Werle 2020). This result is in agreement with the higher thermal degradation peaks observed in Figure 1(b), which may indicate that the reaction progress occurs by a three dimensional diffusion during the devolatilization phase that occurs between $200{ }^{\circ} \mathrm{C}$ and $400{ }^{\circ} \mathrm{C}$ approximately. The higher volatility of the main wood components can probably promote an acceleration in cellulose degradation, not only by generating heat from the heat source itself through the particles, but also by the propagation of hot gases formed by the decomposition of the sample. Several authors also reported that diffusion models controlled the degradation process of lignocellulosic materials (Ornaghi et al. 2020, Poletto et al. 2012, Sobek and Werle 2020).

\section{Reaction half-life time}

The half-life time in thermal degradation reactions can be defined as the interval of time required for one-half of the reactant become product (Bianchi et al. 2008). Therefore, in the present context is the time necessary to one-half of wood degraded by the oxidizing atmosphere. The $t_{1 / 2}$ for each wood specie was obtained for a heating rate of $10^{\circ} \mathrm{C} \cdot \mathrm{min}^{-1}$ at three commonly temperatures used during thermoplastic wood composite processing, $180^{\circ} \mathrm{C}, 200^{\circ} \mathrm{C}$ and $220^{\circ} \mathrm{C}$, as can be seen in Figure 4 . 


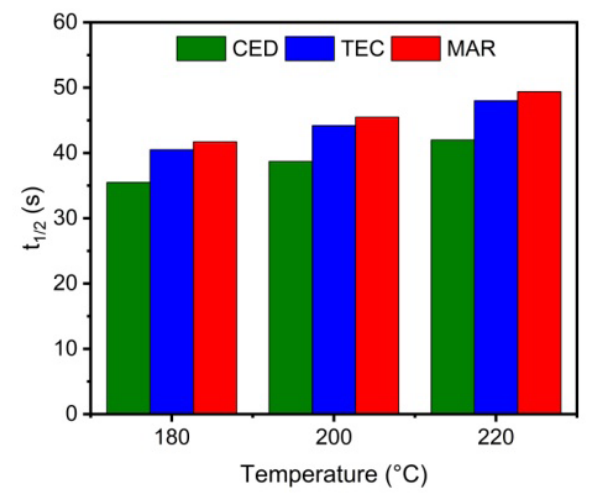

Figure 4: Reaction half-life time for wood species studied at temperatures of 180,200 and $220^{\circ} \mathrm{C}$.

The results indicate that CED wood has the lowest $t_{1 / 2}$ value, while TEC an intermediate value was obtained for TEC and MAR presented the highest half-life time value. The degradation kinetics occurs more sharply in CED wood when compared with TEC and MAR. As previously discussed, CED initiate a mass loss at around $130{ }^{\circ} \mathrm{C}$, the lowest temperature observed for the wood species studied. Probably the higher quantity of gases released during the devolatilization stage can contribute to accelerate the degradation process in this wood which promoting a reduction in the $t_{1 / 2}$ value. On the other hand, the $t_{1 / 2}$ value for CED did not change considerably with the temperature increased, the values ranged from $35 \mathrm{~s}$ to $42 \mathrm{~s}$.

Considering the use of the wood species studied in this work as reinforcement in thermoplastic composites CED will probably present a more pronounced thermal degradation during the processing stages than TEC and MAR. The high shear stress associated with the processing temperatures used for polymer melting during extrusion and injection molding will contribute to CED thermal decomposition and might result in a composite with lower mechanical and thermal properties due to wood degradation.

\section{CONCLUSIONS}

In this study, thermal stability, degradation kinetics and reaction half-life time of three wood species from Brazilian Amazon region were evaluated. Regarding thermal stability, CED wood sample showed the lowest thermal stability initiating a more pronounced thermal degradation process at $130{ }^{\circ} \mathrm{C}$, while TEC and MAR at $190{ }^{\circ} \mathrm{C}$ and $205^{\circ} \mathrm{C}$, respectively. Based on these results, it is not recommended that CED be used at processing temperatures during polymer composite preparation above $130^{\circ} \mathrm{C}$, while for TEC and MAR temperatures higher than $190{ }^{\circ} \mathrm{C}$ were not recommended. FWO results showed dependence of apparent activation energy on conversion degree. Based on the master plots results, the three-dimensional diffusion is the most probable degradation mechanism associated to wood thermal decomposition for the species studied. The CED wood specie has the lowest reaction half-life time which indicate that this wood species can degrade more quicklythan TEC and MAR when as used in composite formulations.

\section{ACKNOWLEDGEMENTS}

The authors are grateful to Madeireira Perimetral for supplied the wood samples.M. Poletto thanks Conselho Nacional de Desenvolvimento Científico e Tecnológico (CNPq/Brazil), grant number 435110/2018-7 for financial support. 


\section{REFERENCES}

Adhikary, K.B.; Pang, S.; Staiger, M.P. 2008. Dimensional stability and mechanical behaviour of wood-plastic composites based on recycled and virgin high-density polyethylene (HDPE). Compos Part B: Eng 39(5): 807-815. https://doi.org/10.1016/j.compositesb.2007.10.005

Ali, I.; Bahaitham, H.; Naibulharam, R. 2017. A comprehensive kinetics study of coconut shell waste pyrolysis. Bioresource Technol 235: 1-11. https://doi.org/10.1016/j.biortech.2017.03.089

AlMaadeed, M.A.; Nógellová, Z.; Mičušík, M.; Novák, I.; Krupa, I. 2014. Mechanical, sorption and adhesive properties of composites based on low density polyethylene filled with date palm wood powder. $M a$ ter Des 53: 29-37. https://doi.org/10.1016/j.matdes.2013.05.093

ASTM. 2018. Standard Test Method for Kinetic Parameters for Thermally Unstable Materials Using Differential Scanning Calorimetry and the Flynn/Wall/Ozawa Method. E698-18. ASTM International: West Conshohocken, PA, United States. https://www.astm.org/Standards/E698.htm

Balogun, A.O.; Lasode, O.A.; McDonald, A.G. 2014. Devolatilisation kinetics and pyrolytic analyses of Tectona grandis (teak). Bioresource Technol 156: 57-62. https://doi.org/10.1016/j.biortech.2014.01.007

Barbos, J.D.V.; Azevedo, J.B.; Cardoso, P. da S.M.; da Costa Garcia Filho, F.; del Río, T.G. 2020. Development and characterization of WPCs produced with high amount of wood residue. J Mater Res Technol 9(5): 9684-9690. https://doi.org/10.1016/j.jmrt.2020.06.073

Batista, D.C.; da Silva, J.G.M.; Andrade, W.S. de P.; Vidaurre, G.B. 2015. Desempenho operacional de uma serraria de pequeno porte do Município de Alegre, Espírito Santo, Brasil. Floresta 45(3): 487-496. https://doi.org/10.5380/rf.v45i3.34441

Bianchi, O.; Martins, J.D.N.; Fiorio, R.; Oliveira, R.V.B.; Canto, L.B. 2011. Changes in activation energy and kinetic mechanism during EVA crosslinking. Polym Test 30(6): 616-624. https://doi.org/10.1016/j. polymertesting.2011.05.001

Bianchi, O.; Oliveira, R.V.B.; Fiorio, R.; Martins, J.D.N.; Zattera, A.J.; Canto, L.B. 2008. Assessment of Avrami, Ozawa and Avrami-Ozawa equations for determination of EVA crosslinking kinetics from DSC measurements. Polym Test 27(6): 722-729. https://doi.org/10.1016/j.polymertesting.2008.05.003

Cabeza, A.; Sobrón, F.; Yedro, F.M.; García-Serna, J. 2015. Autocatalytic kinetic model for thermogravimetric analysis and composition estimation of biomass and polymeric fractions. Fuel 148: 212-225. https:// doi.org/10.1016/j.fuel.2015.01.048

Drozin, D.; Sozykin, S.; Ivanova, N.; Olenchikova, T.; Krupnova, T.; Krupina, N.; Avdin, V. 2020. Kinetic calculation: Software tool for determining the kinetic parameters of the thermal decomposition process using the Vyazovkin Method. Software X 11: 100359. https://doi.org/10.1016/j.softx.2019.100359

Erceg, M.; Krešić, I.; Vrandečić, N.S.; Jakić, M. 2018. Different approaches to the kinetic analysis of thermal degradation of poly(ethylene oxide). J Therm Anal Calorim 131(1): 325-334. https://doi.org/10.1007/ s10973-017-6349-6

Gheith, M.H.; Aziz, M.A.; Ghori, W.; Saba, N.; Asim, M.; Jawaid, M.; Alothman, O.Y. 2019. Flexural, thermal and dynamic mechanical properties of date palm fibres reinforced epoxy composites. J Mater Res Technol 8(1): 853-860. https://doi.org/10.1016/j.jmrt.2018.06.013

Lengowski, E.C.; Bonfatti, E.A.; Nisgoski, S.; Bolzon de Muñiz, G.I.; Klock, U. 2020. Properties of thermally modified teakwood. Maderas-Cienc Tecnol 23(23): 1-16. https://doi.org/10.4067/s0718$221 \times 2021000100410$ 
Li, L.; Zhao, N.; Fu, X.; Shao, M.; Qin, S. 2013. Thermogravimetric and kinetic analysis of Spirulina wastes under nitrogen and air atmospheres. Bioresource Technol 140: 152-157. https://doi.org/10.1016/j.biortech.2013.04.121

Mohd Yusof, N.; Md Tahir, P.; Lee, S.H.; Sabaruddin, F.A.; Mohammad Suffian James, R.; Asim Khan, M.; Lee, C.H.; Roseley, A.S.M. 2020. Thermal properties of Acacia mangium Cross Laminated Timber and its gluelines bonded with two structural adhesives. Maderas-Cienc Tecnol 23(23): 1-10. https://doi. org/10.4067/s0718-221x2021000100402

Neves, R.M.; Lopes, K.S.; Zimmermann, M.V.G.; Poletto, M.; Zattera, A.J. 2019. Characterization of polystyrene nanocomposites and expanded nanocomposites reinforced with cellulose nanofibers and nanocrystals. Cellulose 2: 4417-4429. https://doi.org/10.1007/s10570-019-02392-2

Neves, R.M.; Ornaghi, H.L.; Ornaghi, F.G.; Amico, S.C.; Zattera, A.J. 2020. Degradation kinetics and lifetime prediction for polystyrene/nanocellulose nanocomposites. $J$ Therm Anal Calorim 0123456789. https://doi.org/10.1007/s10973-020-10316-7

Oluoti, K.; Richards, T.; Doddapaneni, T.R.K.; Kanagasabapathi, D. 2014. Evaluation of the pyrolysis and gasification kinetics of tropical wood biomass. BioResources 9(2): 2179-2190. https://doi.org/10.15376/ biores.9.2.2179-2190

Ornaghi, H.L.; Ornaghi, F.G.; Neves, R.M.; Monticeli, F.; Bianchi, O. 2020. Mechanisms involved in thermal degradation of lignocellulosic fibers: a survey based on chemical composition. Cellulose 27(9): 49494961. https://doi.org/10.1007/s10570-020-03132-7

Poletto, M. 2016. Effect of extractive content on the thermal stability of two wood species from Brazil. Maderas-Cienc Tecnol 18(3): 435-442. https://doi.org/10.4067/S0718-221X2016005000039

Poletto, M. 2017. Assessment of the thermal behavior of lignins from softwood and hardwood species. Maderas-Cienc Tecnol 19(1): 63-74. https://doi.org/10.4067/S0718-221X2017005000006

Poletto, M.; Zattera, A.J.; Santana, R.M.C. 2012. Thermal decomposition of wood: Kinetics and degradation mechanisms. Bioresource Technol 126: 7-12. https://doi.org/10.1016/j.biortech.2012.08.133

Ramos, W.F.; Ruivo, M.L.P.; Jardim, M.A.G; Sousa, L.M. 2018. Generation of wood waste from the forest based sector in the metropolitan region of Belém, Pará State. Cienc Florest 28: 1823-1830. http://dx.doi. org/10.5902/1980509835341

Shebani, A.N.; Van Reenen, A.J.; Meincken, M. 2008. The effect of wood extractives on the thermal stability of different wood species. Thermochim Acta 471(1-2): 43-50. https://doi.org/10.1016/j.tca.2008.02.020

Shebani, A.N.; Van Reenen, A.J.; Meincken, M. 2009. The effect of wood extractives on the thermal stability of different wood-LLDPE composites. Thermochim Acta 481: 52-56. https://doi.org/10.1016/j. tca.2008.10.008

Sheshmani, S.; Ashori, A.; Farhani, F. 2012. Effect of extractives on the performance properteis of wood flour-polypropylene composites. J Appl Polym Sci 123: 1563-1567. https://doi.org/10.1002/app.34745

Slopiecka, K.; Bartocci, P.; Fantozzi, F. 2012. Thermogravimetric analysis and kinetic study of poplar wood pyrolysis. Appl Energy 97: 491-497. https://doi.org/10.1016/j.apenergy.2011.12.056

Sobek, S.; Werle, S. 2020. Kinetic modelling of waste wood devolatilization during pyrolysis based on thermogravimetric data and solar pyrolysis reactor performance. Fuel 261: 116459. https://doi.org/10.1016/j. fuel.2019.116459

Tenorio, C.; Moya, R. 2013. Thermogravimetric characteristics, its relation with extractives and chemical properties and combustion characteristics of ten fast-growth speceis in Costa Rica. Thermochim Acta 563: 1221. https://doi.org/10.1016/j.tca.2013.04.005 
Yao, F.; Wu, Q.; Lei, Y.; Guo, W.; Xu, Y. 2008. Thermal decomposition kinetics of natural fibers: Activation energy with dynamic thermogravimetric analysis. Polym Degrad Stabil 93(1): 90-98. https://doi. org/10.1016/j.polymdegradstab.2007.10.012 